\title{
Clarice Lispector, uma flecha em direção ao futuro
}

\section{Entrevista com Júlio Diniz, Silviano Santiago e Florencia}

\section{Garramuño}

\section{Clarice Lispector, an arrow towards the future}

\section{Interview with Júlio Diniz, Silviano Santiago and Florencia Garramuño}

Júlio Diniz é Decano do Centro de Teologia e Ciências Humanas (CTCH) da PUC-Rio e organizador do livro

"Quanto ao futuro, Clarice" (Editora PUC-Rio, 2021). Silviano Santiago é ensaísta, romancista, crítico, poeta e professor emérito da UFF. Florencia Garramuño é diretora do Departamento de Humanidades e do Doutorado em Literatura Latino-Americana e Crítica Cultural da Universidade de San Andrés.

Por Mauro Silveira

Professor do Departamento de Comunicação Social da PUC-Rio e da FACHA. Mestre em Bens Culturais e Projetos Sociais pela FGV-RJ. Pontifícia Universidade Católica do Rio de Janeiro, Departamento de Comunicação, Rio de Janeiro (RJ), Brasil.

Um projeto iniciado a partir do sonho e do desejo de comemorar o centenário de nascimento da escritora Clarice Lispector resultou no livro Quanto ao futuro, Clarice, lançado pela Editora PUC-Rio, em coedição com a Bazar do Tempo. A obra foi idealizada e organizada pelo professor Júlio Diniz, Decano do Centro de Teologia e Ciências Humanas (CTCH) da PUC-Rio, que, para concretizar o objetivo, convidou especialistas na autora - brasileiros e estrangeiros -, encarregados de produzir os 19 ensaios que compõem o livro. O projeto previa para o ano de 2020 uma série de encontros, seminários e uma exposição no Instituto Moreira Salles (IMS). A chegada da pandemia impediu o evento, mas não a 
realização do livro, lançado em dezembro de 2021. Todo esse projeto e, sobretudo, a importância da escritora homenageada foram tema do podcast Som das Ideias, da Editora PUC-Rio. Para participar do episódio, o organizador Júlio Diniz convidou dois ensaístas presentes no livro: o ensaísta, romancista, crítico, poeta e professor Silviano Santiago e a pesquisadora e crítica literária argentina Florencia Garramuño, doutora em Línguas e Literaturas Românicas pela Universidade de Princeton e diretora do Departamento de Humanidades e do Doutorado em Literatura Latino-Americana e Crítica Cultural da Universidade de San Andrés. A Alceu traz um resumo do podcast sobre o livro Quanto ao futuro, Clarice, com depoimentos de Júlio Diniz, Florencia Garramuño e Silviano Santiago.

\section{Professor Júlio, como foi o processo que resultou na realização do livro?}

Júlio Diniz: O projeto começou a partir de um desejo e do sonho de comemoração do centenário de Clarice Lispector. Eu tinha 14 anos quando li o primeiro texto da Clarice, o conto "Feliz aniversário", do livro Laços de família, e nunca mais esqueci. Sempre olhava para minha avó e, principalmente, para minha bisavó, que morreu com 102 anos, pensando no conto. Dos 14 anos até agora, ou seja, há 50 anos, uma boda de ouro, eu sou leitor da Clarice e totalmente seduzido pela literatura dela, que comecei a ler aleatoriamente. Às vezes um conto, um romance, um trecho de uma carta, ou uma crônica. Em 2019 o sonho era esse. Comemorar o centenário em 2020, quando faríamos um encontro, um seminário na PUC-Rio. Veio a pandemia varrendo os sonhos e a possibilidade de realizar o evento. Obviamente fomos atingidos pela pandemia sanitária e por uma outra, de ordem econômica, política, ética e moral. O ano de 2020 custou a passar, e, quando chegou 2021, o projeto do livro continuou na minha cabeça. A duras penas, fomos entrando em contato com os autores, convidamos pessoas, e várias delas aceitaram o convite.

\section{Como o senhor chegou ao título do livro?}

Júlio Diniz: Eu acho que a forma de reagir, não só contra a pandemia e em relação a tudo que estava acontecendo no Brasil na política, economia, foi também publicar esse livro. E não é à toa que um dos 13 títulos de A hora da estrela, "Quanto ao futuro", foi o mote para batizar este livro. E seria Quanto ao futuro, Clarice. A ideia básica era jogar Clarice como flecha ao futuro. Ou seja, não era fazer um evento ou 
um livro monumental, um tributo ao passado, ou seja, nostálgico de uma certa maneira, melancólico, exaltando a Clarice, monumentalizando a Clarice. Era muito mais ler a Clarice no presente e poder convidar os futuros leitores a ler Clarice a partir de agora. E nós tivemos total apoio do Paulo Gurgel Valente, filho da Clarice, que nos liberou inúmeras imagens, trechos de textos. Em parceria com a editora Bazar do Tempo, convidei 19 ensaístas, que puderam contribuir de maneira singular nessa constelação Clarice, nesse mapeamento de toda a obra da Clarice. Alguns textos falam de aspectos biográficos e da correspondência da Clarice. Eu acho que são textos que apontam para caminhos diferentes da obra, da vida, da trajetória da Clarice. Além disso, no Núcleo de Memória da PUC-Rio existem inúmeras fotos que foram tiradas em 1975 no encontro de professores de Literatura. Em algumas fotos, a escritora foi retratada ao lado de suas duas grandes amigas Marina Colasanti e Nélida Piñon. Essas fotos constam no livro e são uma marca, uma impressão digital da PUC. A professora Margarida de Souza Neves, que coordenava na época o Núcleo de Memória, fez um belo texto sobre essas fotos e sobre esse processo. Convidei Marina Colasanti e Nélida Piñon a dar depoimento sobre esse encontro em 1975. E, para fechar o livro, eu convidei Maria Bethânia para dar um depoimento, dado que, desde os anos 1970, em quase todos os seus shows, Bethânia popularizou Clarice por meio da interpretação de seus textos.

\section{Professora Florencia, como tradutora de Clarice, a senhora poderia dizer que qualidades a escritora possui para atrair leitores de outros países?}

Florencia Garramuño: A primeira vez que li Clarice - talvez Água viva - foi uma tradução em castelhano na Argentina. Estava entrando na universidade, nos anos 1980, época em que não havia muitos livros de Clarice traduzidos. Embora tivesse gostado, achava que o livro não dizia muito da literatura pela qual eu estava interessada, que era a literatura contemporânea. Mas depois, por situações um pouco mais profissionais, quando fiz o doutorado, meu primeiro trabalho foi dar aulas de literatura brasileira e portuguesa, nos Estados Unidos. Eram cursos que abordavam os escritores mais importantes. Comecei a ensinar Clarice Lispector no momento em que estava terminando minha tese de doutorado sobre as literaturas contemporâneas brasileira e argentina. Na época, comecei outra pesquisa, sobre a literatura dos anos 1970 e 80 . Foi quando comecei a ver que todos aqueles jovens escritores, mas também cineastas, músicos como Caetano Veloso, todos falavam da Clarice como uma deusa. Constatei que a literatura dela atraía um interesse muito grande por parte dos jovens, como Caio Fernando Abreu, Silviano Santiago, João 
Gilberto Noll, que achava Clarice uma inspiração. Comecei a pensar que, na verdade, Clarice Lispector tinha, de alguma forma, um futuro da literatura - não só brasileira, como da própria literatura - quando ela estava entrando em um processo de transformação muito forte. Eu acho que, nos anos 1970, para os países da América Latina, e sobretudo do Cone Sul, que transitavam em violentas ditaduras, a literatura entrou num processo de transformação do próprio estatuto do literário. Acho que a literatura da Clarice Lispector, já em seus primeiros romances, é muito diferente daquilo que a literatura brasileira era nos anos 1940. Eu acho que ela já estava lançando uma linha para o futuro. Adorei que o Júlio tenha escolhido Quanto ao futuro para o título porque eu não me lembrava desse título entre os outros de $A$ hora $d a$ estrela. Mas ela publicou uma crônica nos anos 70, no Jornal do Brasil, que se chama "Inauguração do futuro". E, no Água viva, ela tem um fragmento, depois retirado do livro, mas que está num dos manuscritos, que diz: "há uma linha de aço atravessando o presente". A literatura de Clarice também era influenciada por esses autores jovens e toda essa movimentação na cultura da época. Era uma literatura muito sedutora para os jovens porque vai ser a literatura que eles vão escrever. São textos curtos de uma literatura menos preocupada com gêneros muito estabelecidos, menos preocupada com a diferenciação entre ficção e realidade, menos preocupada com uma voz autoral, patriarcal. Essa é a literatura contemporânea e é a literatura que a Clarice Lispector de algum modo inaugurou nos anos 70. É muito interessante ver como, pelo menos na Argentina e na América Latina, mesmo já sendo uma escritora conhecida, ela nunca foi tão famosa como agora. Isso também é algo que me faz pensar que a literatura contemporânea é muito mais receptiva a Clarice do que a literatura que foi contemporânea a ela, sobretudo a literatura da geração dela. Uma literatura que inaugurou a literatura mais solta, que é a nossa literatura contemporânea.

\section{Professor Silviano, como pode ser analisada a literatura de Clarice Lispector em seus primeiros anos como escritora?}

Silviano Santiago: Acho que eu, enquanto leitor de Clarice, vivi mais anos do que Clarice. Isso para mim é uma coisa fantástica. Eu gostaria muito de começar sobre o que é você poder viver, conviver, sobreviver a uma obra da importância de Clarice Lispector. Se não me engano, é o único caso na minha vida em que eu pude perseguir uma determinada obra por mais anos do que os anos que vivi. Eu começo a ler Clarice, totalmente por acaso, em 1952 e acho que Florencia foi muito feliz quando usou algumas vezes a palavra 


\section{ALCEU}

ISSN: 2175-7402

"inaugurou". Acho que isso é que é importante. Não só em Clarice Lispector, como também em Machado de Assis. Eu acho que por isso Machado e Clarice são os grandes autores brasileiros que são passíveis de exportação. São dois autores que inauguram a literatura. O que entendo por inaugurar a literatura? Permitam-me a licença poética, sei que Machado de Assis não estreou com essa obra, mas para mim ele começou com Memórias póstumas de Brás Cubas, assim como Clarice estreou logo com sua primeira obra, Perto do coração selvagem. Isso demonstra a genialidade de Clarice, enquanto Machado de Assis era um trabalhador braçal. Mas são os únicos dois livros que inauguram, na literatura brasileira, a literatura. Por que eu digo inaugurar? Porque esses dois livros foram escritos com tal imaginação, em tal delírio e em tal devaneio de grandeza, que eles escreveram para um leitor que não existia. O leitor brasileiro de Memórias póstumas de Brás Cubas e o leitor brasileiro de Perto do coração selvagem não existiam. Não havia ninguém preparado - e eu posso confessar isso - para ler aquele livro. É isso que eu chamo de livro inaugural. De repente você está diante de um objeto que escapa completamente ao quadro de referências pré-estabelecido. Vou usar o exemplo de Muhammad Ali, o lutador que baixava a guarda. No boxe, baixar guarda significa não proteger o rosto quando está recebendo o ataque mais furioso do adversário. Diante de Memórias póstumas de Brás Cubas e Perto do coração selvagem, eu tive que baixar a guarda. Tudo o que tinha aprendido, toda a minha formação, não valia nada. Como diz a Florencia, esses autores são do futuro agora. De repente temos uma tal proposta de revolução na literatura brasileira que a crítica é obrigada a baixar a guarda. Nós não estamos sabendo muito o que está sendo escrito e o que poderá vir desta nova geração. É isso que me fascina em Clarice. O crítico Antonio Candido foi muito feliz quando disse que Clarice inventa o mundo partindo de suas emoções, de suas sensações. Esse inventar o mundo a partir de suas sensações, não é isso que esta nova geração está querendo hoje em dia? Um novo mundo a partir de sensações que desconhecemos, mas fantasiamos, que nós criamos até em literatura, em cinema ou o que seja, mas onde nunca tivemos o lugar de fala. É isso que eu acho interessantíssimo no romance de Clarice, que continuará posteriormente. Essa afinidade, então, é uma maneira de criar a constelação, que é riquíssima, para os pósteros, para mim jovem. Eu tive até hoje a sorte de ter vivido esses muitos anos em companhia de Clarice. Não sou especialista em Clarice, nunca quis ser. Eu quis sempre abordar a partir de pequenos aspectos. Mas é aí, nesses pequenos detalhes, que o diabo de Machado de Assis e Clarice Lispector se esconde. 


\section{Professora Florencia, é possível considerar Clarice Lispector uma escritora popular, hoje?}

Florencia Garramuño: Em sua maioria, os romances da Clarice foram recebidos muito calorosamente pela crítica e por críticos já há muito importantes. Mas ela não foi muito lida. A discussão da literatura de Clarice Lispector começa, realmente, nos anos 70. Na Argentina, por exemplo, só há uns 15 anos começaram a ser retraduzidos alguns desses primeiros romances. Na Editorial Corrigidor, abriu-se uma série específica sobre a biblioteca Clarice Lispector que tem traduzido todos os livros dela. Esses livros, na Argentina, vendem como pão quente, para leitores muito novos. Eu faço uma piada dizendo que a Clarice virou um tipo de estrela do rock porque está em toda a parte. Tem bonequinhas com a Clarice Lispector, as pessoas tatuam no corpo frases da Clarice. Isso é muito interessante, por exemplo, quando penso que, para mim, a Clarice é a primeira escritora latino-americana que escreve não como um homem. Isso não quer dizer que ela escreva como uma mulher; obviamente há muitas escritoras mulheres anteriores muito interessantes, mas de alguma forma as estruturas narrativas que elas vão preencher com uma sensibilidade diferente são estruturas herdadas da tradição. Eu acho que o que a Clarice faz é de alguma forma quebrar essas estruturas e, como na fala do Antonio Candido lembrada por Silviano, criar um mundo novo a partir de novas emoções. Isso faz com que ela vá abrindo essas estruturas, não só as preenchendo com uma sensibilidade diferente, mas deixando-se dirigir pelas emoções.

\section{Professor Júlio, qual é o papel do trabalho de Clarice Lispector na imprensa na formação do seu público?}

Júlio Diniz: Clarice escrevia para jornal e para revista e, com isso, chegava a leitores que não eram os do livro. Mas, com isso, muita gente começou a ler. Há um episódio que Maria Bethânia narra no livro em que o pai dela, Zeca, fez uma assinatura da revista Senhor, que assim chegava a Santo Amaro, no Recôncavo Baiano. Primeiro a ler a revista, Caetano Veloso indicava para a irmã os textos de Clarice, dizendo que iria gostar por ser uma escritora incrível como ela. Dessa forma, Clarice começou a ser lida por Bethânia na revista. Eu mesmo a acompanhava e lia, até que um dia ela foi demitida do JB, onde escrevia. Ou seja, existe uma formação de público leitor. Eu li Clarice primeiro na escola, uma formação absolutamente convencional do leitor escolarizado. Mas a Clarice estava dispersa. Então é tão curioso isto: o fato de que Clarice, Fernando Pessoa e Guimarães Rosa são os autores mais citados e da maneira mais enlouquecida, 
errônea, equivocada e inapropriada possível nas redes sociais. São muitas frases erradas que as pessoas utilizam como epígrafe. Parece que o texto da Clarice servia a mil propósitos.

\section{Professor Silviano, como o senhor analisa a utilização das epígrafes, observada pelo professor Júlio?}

Silviano Santiago: Eu acho que Clarice tem um recurso que considero extremamente sofisticado e que pode eventualmente explicar a questão das epígrafes. Clarice descobre uma coisa tipicamente latinoamericana: os aforismos. De repente você pode ler um livro dela destacando os aforismos que seriam de La Rochefoucauld, que é o grande moralista do século XVIII. É uma maneira de você, em um texto que é obscuro, de difícil acesso, lançar uma determinada frase que captura o leitor, captura o olhar, e que obviamente empurra o leitor para continuar bem a leitura. Eu acho que esse é o mesmo efeito da crônica, por exemplo, em Carlos Drummond. Ele tinha um truque de dizer que havia acabado de receber uma carta de um leitor que comentava tal coisa. Um truque para trazer o leitor para a crônica. Você não pode trazer o leitor para o romance, a não ser com as célebres interjeições "meu caro leitor", "minha cara leitora". Pelo jornal você pode trazer o leitor para o seu próprio universo. Eu acho que uma dessas maneiras que são fascinantes em Clarice são determinados recursos que você vê em muitos escritos dela de jornal, como o uso de uma série de aforismos.

\section{Professor Júlio, uma pergunta que o senhor faz no livro às convidadas que deram depoimento: que mistério tem Clarice?}

Júlio Diniz: Na verdade, acho que o mistério da Clarice está justamente na impossibilidade de decifração desse próprio mistério. A Clarice é um moto-contínuo nesse sentido. Não é à toa que ela está aqui, neste moto-contínuo. O futuro, quando a gente pensou no livro, jamais seria futuro do pretérito, mas o futuro do presente. A Clarice está o tempo inteiro nesse lugar de interrogação. Existe toda uma leitura que acaba mistificando Clarice por muitas razões. Ela é uma personagem, temos que entender isso. Ela vestia as máscaras dessa personagem. O próprio Silviano estava apontando esses truques, na verdade esses lugares. Eu diria que a própria personagem Clarice, no dia a dia, era exatamente isso. Uma vez perguntei se a música Clarice (Caetano Veloso e José Carlos Capinam), cujo refrão faz a pergunta "Que mistério tem 
Clarice", era para ela. Não era, mas serve para Clarice também. Fiz a pergunta como uma provocação para Marina Colasanti, Nélida Piñon e Maria Bethânia no livro, e cada uma vai dar uma resposta das maneiras mais distintas a essa pergunta sobre a Clarice, que cultivava o mistério, todo esse jogo de máscaras, na sua própria vida. Enfim, uma personagem.

(Clique aqui para ouvir a entrevista na íntegra)

Mauro Silveira

ORCID: https://orcid.org/0000-0001-9928-3618 Pontifícia Universidade Católica do Rio de Janeiro, Departamento de Comunicação, Rio de Janeiro (RJ), Brasil. Mestre em História, Política e Bens Culturais / FGV-RJ E-mail:mauro.silveira05@gmail.com

Recebido em: 8 de dezembro de 2021.

Aprovado em: 15 de dezembro de 2021.

Este artigo é publicado em acesso aberto (Open Access) sob a licença Creative Commons Attribution Non-Commercial (CC-BY-NC 4.0), que permite que outros remixem, adaptem e criem a partir do seu trabalho para fins não comerciais, e embora os novos trabalhos tenham de lhe atribuir o devido crédito e não possam ser usados para fins comerciais, os usuários não têm de licenciar esses trabalhos derivados sob os mesmos termos. 